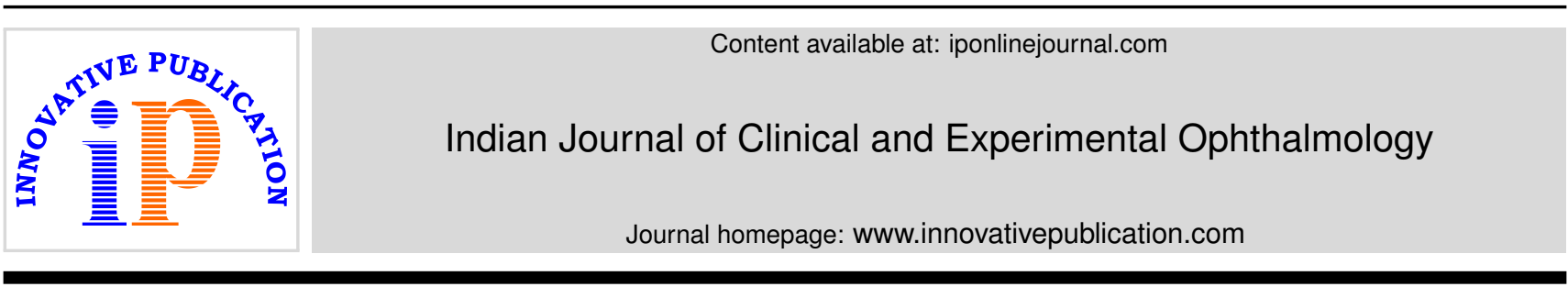

Original Research Article

\title{
The clinical profile and aetiological pattern of anterior uveitis- A hospital based study
}

\author{
Nithisha Tegginamatha ${ }^{1}$, Prathibha Shanthaveerappa ${ }^{1}$,*, Remya Parappallil ${ }^{1}$ \\ ${ }^{1}$ Dept. of Opthalmology, Rajarajeswari Medical College and Hospital, Bangalore, Karnataka, India
}

\section{A R T I C L E I N F O}

\section{Article history:}

Received 29-08-2019

Accepted 20-11-2019

Available online 17-03-2020

Keywords:

Anterior uveitis

Behcets disease

Granulomatous

Tuberculosis

\begin{abstract}
A B S T R A C T
Introduction: Uveitis is a group of complex inflammatory disorder of the uveal tract with diverse aetiology. The most common formis anterioruveitis affecting the iris and pars plicata of the ciliary body which can lead to severe vision threatening complications if not treated appropriately.

Objectives: 1 . To study the incidence, modes of presentation and etiological patternof anterior uveitis. 2 . To evaluate the treatment, its outcome and the complications that could occur over the study period.

Materials and Methods: A prospective cross sectional clinical study was conducted in the department of ophthalmology in 30 patients who were clinically diagnosed with anterior uveitis over a period of one year. All the patients underwent adetailed ophthalmic evaluation and relevant laboratory investigations. They were givenappropriate treatment according to the cause and the clinical clues and were also followed up for anycomplication during the study period.

Results: Anterior uveitis occurred most commonly in the 41 to 50 years age group. Majority of the cases had nongranulomatous inflammation (86\%) but aetiology remained unknown in $30 \%$ of the cases. Herpetic infection (16\%) was the commonest cause followed by phacolyticuveitis and tuberculosis. Most cases responded favourably to medical management.

Conclusion: A balanced view of the disease needs to be taken while investigating and treating anterior uveitis. A thorough history and physical examination is required in each case to facilitate a final diagnosis. A timely diagnosis and appropriate treatment however can improve visual outcome.
\end{abstract}

(C) 2020 Published by Innovative Publication. This is an open access article under the CC BY-NC-ND license (https://creativecommons.org/licenses/by/4.0/)

\section{Introduction}

Uveitis is defined as the inflammation of the entireuveal tract affecting any of its three constituents- iris, ciliary body or choroid. Many systemic diseases may have uveitis as their presenting feature and diagnosing them early can prevent their progression. ${ }^{1}$ Anterior uveitis is the most common form of uveitis $(57.4 \%){ }^{2}$ In the pathogenesis of several uveitic entities, autoimmune mechanism plays a very significant role rather than infection or trauma. ${ }^{3}$ The treatment of uveitis itself can cause several ocular and systemic side effects. ${ }^{4-6}$ This study was undertaken to evaluate the modes of presentation, aetiology and complications of anterior uveitis.

\footnotetext{
* Corresponding author.

E-mail address: prathibhas@ rediffmail.com (P. Shanthaveerappa).
}

\section{Materials and Methods}

A prospective observational study was conducted in the Department of Ophthalmologyin 30 patients with anterior uveitis whom we decided to include in the study after obtaining their informed consent. Anterior uveitis following ocular injuries (open or closed globe), infective corneal ulcers, recent intraocular surgeries and those associated with other uveitic entities like intermediate, posterior or pan uveitis were not included in the study. All the patients were evaluated with detailedhistory and ocular examination, which included visual acuity assessment, slit lamp examination, IOP measurement andposterior segment examination. Every patient was approached with a differential diagnosis based on the case history and clinical picture. The laboratoryinvestigation were tailored for each 
case which included Hemogram, erythrocyte sedimentation rate, $\mathrm{C}$ reactive protein, urine analysis, Mantoux test, serological tests like HIV, VDRL and rheumatoid factor. Radiological investigations included x-ray of chest and lumbosacral joints. Other investigations like quantiferon gold test, HLA-B27, ANA, ANCA and ACE levels were done whenever necessary. The aetiology was defined idiopathic in those patients in whom the above tests were negative.

All patients were treated with topical steroids and cycloplegics and the response in most of the cases were prompt and satisfactory. Specific therapy (eg antivirals and immunosuppressants) were given whenever aetiology was known. Cataract extraction was done in patients with lensinduced inflammation after the attack subsided with medical treatment. Patients with secondary glaucoma were treated with antiglaucoma drugs. All the patients were followed up at planned intervals and any complications they developed during this course were recorded.

\section{Results}

A total of 30 patients with anterior uveitis were studied and the following observations were made. Table 1 summarizes the sociodemographic data of the study participants. The aetiological distribution of cases are summarized in Table 2. The type of inflammation and their clinical presentation are graphically represented in Graph 1 and Graph 2 respectively. The complications that the study subjects developed during the study period is represented in Graph 3.

Table 1: Summarizes the sociodemographic data of the study participants

\begin{tabular}{lll}
\hline Age (in years) & No. of patients & Percentage \\
$<10$ & 1 & $3.3 \%$ \\
$11-20$ & 1 & $3.3 \%$ \\
$21-30$ & 3 & 10 \\
$31-40$ & 5 & $16.6 \%$ \\
$41-50$ & 8 & $26.6 \%$ \\
$51-60$ & 7 & $23.3 \%$ \\
$61-70$ & 5 & $16.6 \%$ \\
Sex distribution & & \\
Males & 18 & 60 \\
Females & 12 & 40 \\
Laterality & & \\
Unilateral & 26 & $86.7 \%$ \\
Bilateral & 4 & $13.3 \%$ \\
\hline
\end{tabular}

\section{Discussion}

In this prospective study of 30 patients, the specific diagnosis for an intraocular inflammation was not established in $30 \%$ of cases. This correlates with other studies where they have reported the cause being unknown in 30-60\% of patients. ${ }^{7-9}$ Systemic disease which could cause the



Graph 1: Type of inflammation

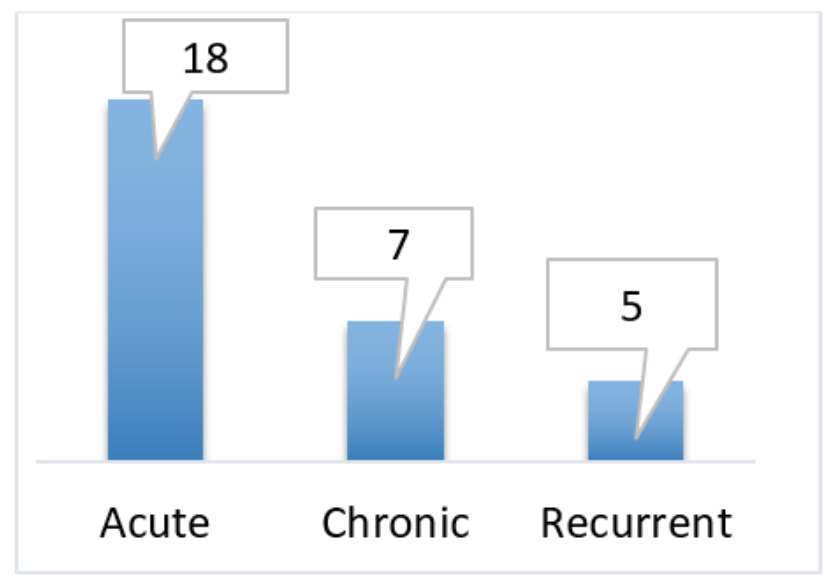

Graph 2: Clinical presentation

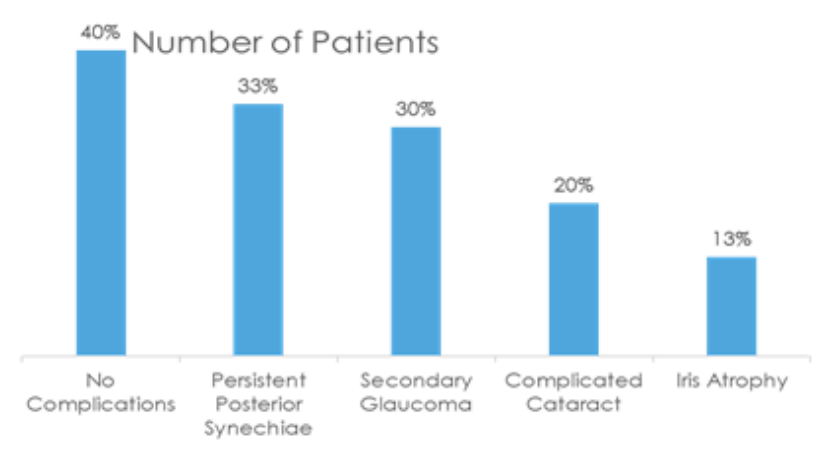

Graph 3: Complications of anterior uveitis 
Table 2: Aetiological distribution of cases

\begin{tabular}{lll}
\hline Aetiology & No of patients & Percentage \\
Idiopathic & 9 & $30 \%$ \\
Herpetic infection & 5 & $16.6 \%$ \\
Lens induced & 4 & $13.3 \%$ \\
Tuberculosis & 4 & $13.3 \%$ \\
Blunt trauma & 3 & $10 \%$ \\
Spondyloarthropathy & 3 & $10 \%$ \\
Behcets disease & 2 & $6.6 \%$ \\
\hline
\end{tabular}

intraocular inflammation was determined in $30 \%$ of all cases and such systemic disease causing uveitis varies from less than 19 to $46 \%$ in various studies. ${ }^{10,11}$

In our study, the incidence of anterior uveitis was high in 41-50 yrs age group (26.6\%). In older age group, uveitis was phacolytic in origin. Males $(60 \%)$ were affected more than females in this study which was comparable with Rathinam et al study $(61.3 \%) .{ }^{12}$ This may be because socioeconomic habits put male patients at a greater risk for development of uveitis and hence they seek medical aid more than women who manages initially with home remedies. Majority of the patients had unilateral anterior uveitis $(86.6 \%)$ which corresponds with the study by Rathinam SR et al in which majority $(85.3 \%)$ had unilateral involvement.

The most common presentation was acute iridocyclitis (60\% of patients) followed by chronic (23.3\%). This was comparable to Sudha Madhavi et al. from Karnataka reported about $75.6 \%$ acute uveitis and $17.8 \%$ of chronic uveitis. ${ }^{13}$ Nongranulomatous inflammation was seen in majority of the cases and this is comparable with the previous studies. ${ }^{8,12}$ Granulomatous type of inflammation (Graph 1) was seen in 4 patients diagnosed with pulmonary tuberculosis.

In the present study, herpetic infection (16.6\%) was the most common identified cause of anterior uveitis followed by lens induced inflammation (13.3\%) and tuberculosis (13.3\%). This was comparable with Rathinam et al. and Singh et al. study where herpetic infection stood first. 3 patients had spondyloarthropathy and 2 patients who presented with hypopyon and aphthous ulcer were diagnosed to have behcets disease (Graph 2). All the patients responded favorably to medical treatment. Cataract surgery was performed in 5 patients once the inflammation was controlled. $40 \%$ of the patients recovered without any complications. The most common complication observed was persistent posterior synechiae (33\%) (Graph 3) followed by secondary glaucoma (30\%), complicated cataract $(20 \%)$ and Iris atrophy $(13 \%)$. None of these cases had posterior segment pathology. Rothova et al. reported cataract in $19 \%$ of cases and glaucoma in $11 \% .^{14}$

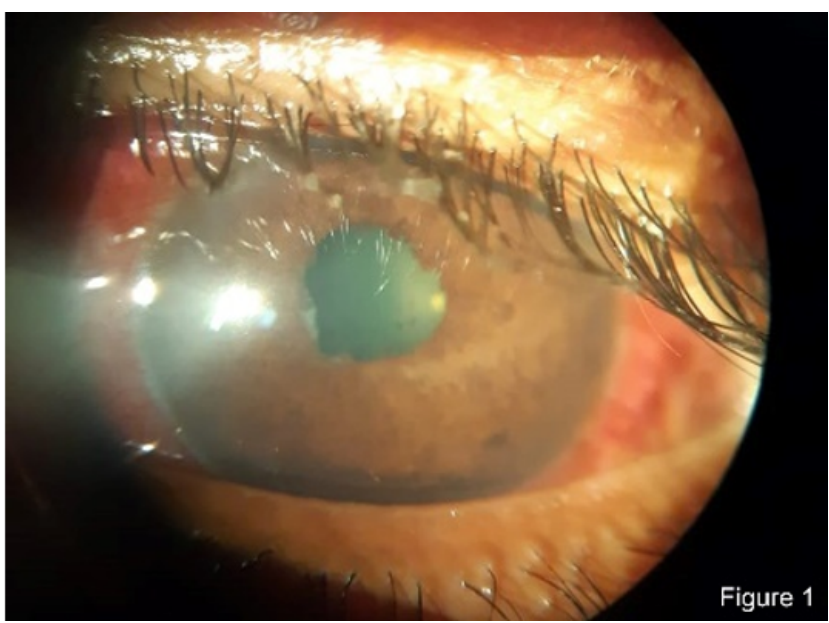

Fig. 1: Granulomatous inflammation showing koeppe nodules in the pupillary margin and busacca nodules on the surface of iris with mutton fat keratic precipitates
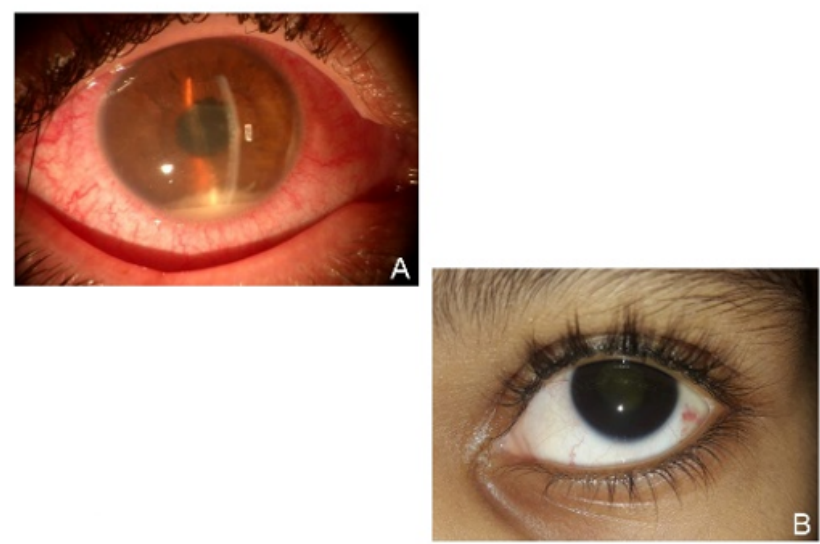

Fig. 2: Behcets disease- A: Before the treatment showing circumciliary congestion and frank hypopyon. B: After the treatment showing a quiet eye with resolved hypopyon

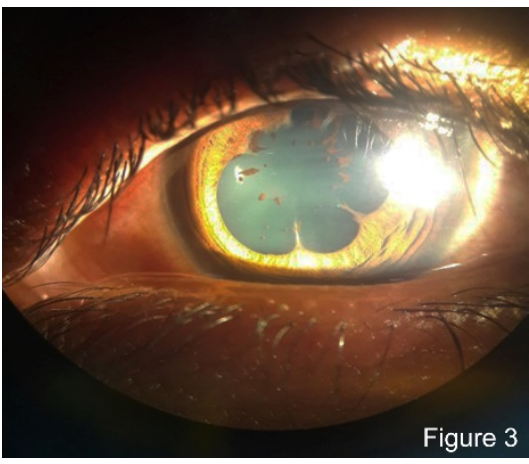

Fig. 3: Posterior synechiae. 


\section{Conclusion}

Anterior uveitis is a vision threatening disease with varied causes but mostly the aetiology remains unknown. In some cases, the systemic diseases manifesting as uveitis could be recognized only during the detailed work up for uveitis. This was beneficial as some potential complications of these systemic diseases could be prevented by timely detection and treatment of these disorders. Investigations should be ordered keeping in mind the availability and cost factor and a tailored work up depending on age, history, clinical examination would be appropriate. Hence, a prompt diagnosis and early initiation of treatment can save the vision without significant sequelae.

\section{Source of Funding}

None.

\section{Conflict of Interest}

None.

\section{References}

1. Rathinam SR. CME series. All India Ophthalmological Soceity. Uveitis made simple-Work up and management.

2. Nussenblatt RB, Whitcup SM. Uveitis fundamentals and clinical practice. 3rd edition. Pennysylvania: Mosby; 2004.

3. Yanoff M, Duker JS, Augsburger JJ, Azar DT, Diamond GR, et al. Ophthalmology Missouri (MO). Mosby; 2004.

4. Venkataraman A, Rathinam SR. A pre- and post treatment of vision related quality of life in uveitis. IJO. 2008.

5. Duke-Elder S, Perkins ES. Diseases of the Uveal Tract;9:39-594.
6. Opremack EM, Winningham ET, Foster CS, Forster D, Moorthy RS. Basic and Clinical Science Course. AAO; 2006.

7. Singh R, Gupta V, Gupta A. Pattern of uveitis in a referral eye clinic in North India: IJO ; 2004.

8. Rodriguez A, Calonge M, Pedroza-Seres M, Akova YA, Messmer EM, et al. Referral pattern of uveitis in a tertiary eye care centre. Arch Ophthalmol. 1996;114:593-599.

9. Khairallah M, Yahia SB, Ladjimi A, Messaoud R, Zaouali S, et al.. Pattern of uveitis in a referral centre in Tunisia, North Africa.

10. Wakefield D, McCluskey PJ, Dunlop I, Penny R. Uveitis: Aetiology and disease associations in an Australian population. Aust NZJ Ophthalmol. 1986;14(3):181-187.

11. Rosenbaum JT. Uveitis. An internist's view. Arch Intern Med. 1989;149(5):1173-1176.

12. Rathinam SR, Namperumalsamy P. Global variation and pattern changes in epidemiology of uveitis. Indian $J$ Ophthalmol. 2007;55(3):173-183

13. Kumaraswamy RC, Madhavi KS. Study of clinical and aetiological pattern of anterior uveitis in middle Karnataka. J Health Resh. 2015;2:124-128. d01:10.4103/2348-3334, 153256

14. Rothova A, van Schulten MSS, Treffers WF, Kijlstra A. Causes and frequency of blindness in patients with intraocular inflammatory disease. Br J Ophthalmol . 1996;80(4):332-336.

\section{Author biography}

Nithisha Tegginamatha Professor

Prathibha Shanthaveerappa Assistant Professor

Remya Parappallil Junior Resident

Cite this article: Tegginamatha N, Shanthaveerappa P, Parappallil R. The clinical profile and aetiological pattern of anterior uveitis- A hospital based study. Indian J Clin Exp Ophthalmol 2020;6(1):99-102. 